\title{
Zinc-Catalyzed Cyclopropenation of Alkynes via 2-Furylcarbenoids
}

\author{
María J. González, Luis A. López* and Rubén Vicente* \\ Departamento de Química Orgánica e Inorgánica and Instituto de Química Organometálica “Enrique Moles”, Universidad de \\ Oviedo. C/ Julián Clavería 8, 33006-Oviedo, Spain. e-mail: lalg@uniovi.es, vicenteruben@uniovi.es
}

Supporting Information Placeholder
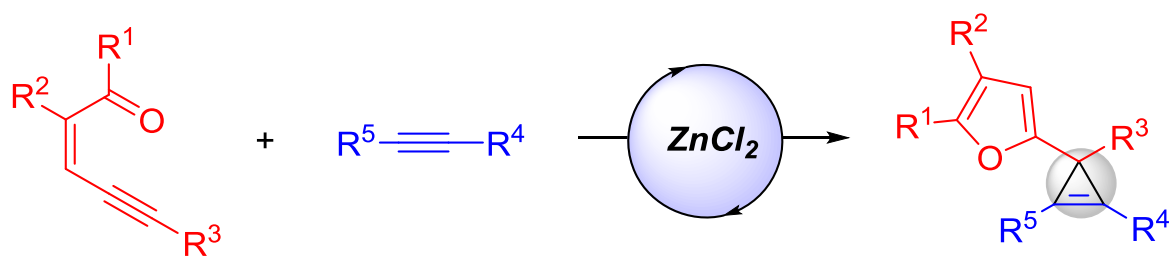
ABSTRACT: An unprecedented cyclopropenation reaction of alkynes catalyzed by $\mathrm{ZnCl}_{2}$ is reported. While Simmons-Smith-type
carbenoids failed in the [2+1]-cycloaddition with alkynes, the use of enynones as the carbene source enables the preparation of
substituted 2-furyl cyclopropene derivatives with remarkable scope.

Strained three-membered carbocycles, namely cyclopropanes and cyclopropenes, are a class of compounds that fascinated chemists for years. ${ }^{1}$ The particular physical properties of these compounds translate into an incomparable reactivity, which has been fruitfully exploited in organic synthesis. ${ }^{2}$ The Simmons-Smith reaction, discovered in $1958,{ }^{3}$ described the first modular synthesis of cyclopropanes using alkenes and $\mathrm{CH}_{2} \mathrm{I}_{2}$ as $\mathrm{C} 1$ synthon in the presence of stoichiometric amounts of the zinc-copper couple. Subsequent studies on this transformation have enabled the establishment of broadly applicable and reproducible reaction conditions using an excess of $\mathrm{Et}_{2} \mathrm{Zn}$ (Furukawa's protocol). ${ }^{4}$ Species such as $\mathrm{XCH}_{2}-\mathrm{ZnY}$ or $\left(\mathrm{XCH}_{2}\right)_{2} \mathrm{Zn}(\mathrm{X}=$ halogen $)$ are nowadays accepted as the zinc intermediates involved in the cyclopropanation reaction (Scheme 1, a). ${ }^{5}$ In contrast to the reaction with alkenes, the Simmons-Smith reaction proved inapplicable to alkynes, making this synthetic strategy towards the corresponding cyclopropenes unrealizable. ${ }^{6,7}$ Indeed, the use of terminal alkynes gives rise to $\mathrm{C}-\mathrm{H}$ bond insertion products in low yields, while the corresponding cyclopropenes were not observed. ${ }^{6 a}$ Moreover, the reaction with internal alkynes led to complex reaction mixtures. $^{6 \mathrm{~b}}$

In the last years, we have started a research devoted to the development of zinc-catalyzed processes with potential relevance to organic synthesis. ${ }^{8,9}$ Among others, we reported the $\mathrm{ZnCl}_{2}$-catalyzed cyclopropanation reaction of alkenes using enynones as carbene precursor (Scheme $1, \mathrm{~b}) .{ }^{8 \mathrm{a}}$ Computational studies suggested the participation of a furyl Fischer-type zinc carbenoid intermediate. On the contrary, the involvement of a zinc intermediate structurally related to those proposed in the Simmons-Smith reaction is unlikely due to its higher energy compared to the furyl carbene. Also, the absence of a reaction pathway connecting with the final cyclopropane argues against the role of Simmons-Smith-like intermediate in the transformation. ${ }^{8 \mathrm{a}}$
Considering the structural difference of both intermediates, we believed that this contrast might influence the reactivity towards alkynes allowing the access to cyclopropene derivatives. Herein, we reported our findings on an unprecedented zinc-catalyed cyclopropenation reaction with alkynes.

Scheme 1. Cyclopropanation vs cyclopropenation reactions involving Zinc.

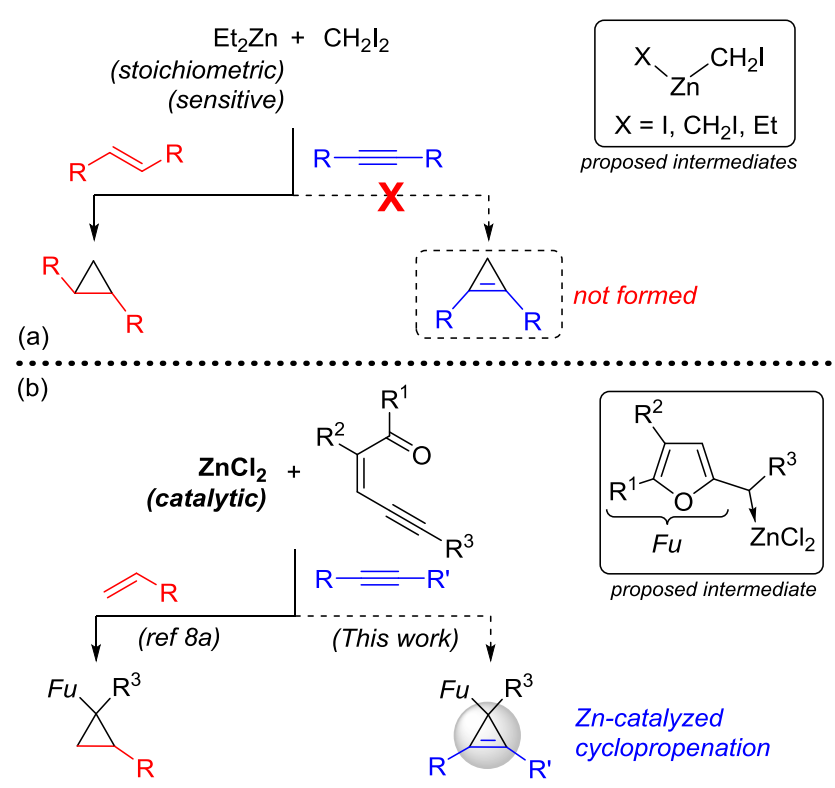

Enynone 1a and a terminal alkyne as phenyl acetylene 2a were selected as model substrates to evaluate the feasibility to achieve zinc-promoted cyclopropenation reactions (Scheme 2 ). At the outset, we used reaction conditions analogous to 
those employed with alkenes, ${ }^{8 \mathrm{a}}$ specifically $\mathrm{ZnCl}_{2}(10 \mathrm{~mol} \%)$, an excess of $\mathbf{2 a}$ (6.0 equiv) in $\mathrm{CH}_{2} \mathrm{Cl}_{2}$ at ambient temperature. Gratifyingly, we observed the formation of the desired cyclopropene $3 \mathbf{a}$ in a moderate $48 \%$ yield. A subsequent study of the reaction conditions allowed us to isolate compound $\mathbf{3 a}$ in $58 \%$ yield after column chromatography when decreasing the reaction temperature to $0{ }^{\circ} \mathrm{C}$. At lower temperatures, the transformation occurred with very low conversions at long reaction times. Other commercially available zinc salts proved slightly less effective than $\mathrm{ZnCl}_{2}$. Among other solvents, only toluene provided similar results, while reducing the amount of $\mathbf{2 a}$ led to a significant decrease in the yield. Remarkably, the preparation of compound $\mathbf{3 a}$ represents the first example of a cyclopropenation of an alkyne using a zinc salt as the catalyst.

Scheme 2. Zinc-catalyzed cyclopropenation of 2a: Screening.

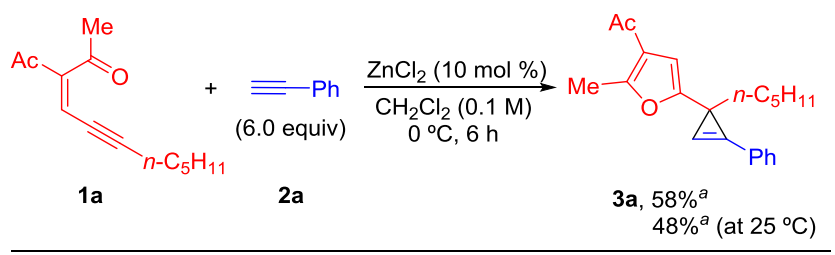

Modifications of the standard conditions

\begin{tabular}{|c|c|c|}
\hline Catalyst & Solvent & Alkyne equiv \\
\hline $\mathrm{ZnBr}_{2} ; \mathbf{3 a}, 49 \%^{b}\left(\right.$ at $\left.0{ }^{\circ} \mathrm{C}\right)$ & $\mathrm{PhMe} ; \mathbf{3 a}, 55 \%^{a}$ & $2 \mathbf{a}$ (3.0 equiv); $3 \mathbf{a}, 47 \%^{b}$ \\
\hline $\mathrm{ZnI}_{2} ; 3 \mathrm{a}, 50 \%{ }^{b}\left(\right.$ at $\left.0{ }^{\circ} \mathrm{C}\right)$ & THF; $\mathbf{3 a}, 27 \%\left[{ }^{[\mathrm{b}]}\right.$ & $2 \mathbf{a}$ (1.5 equiv); $3 \mathbf{a}, 39 \%^{b}$ \\
\hline $\mathrm{Zn}(\mathrm{OTf})_{2} ; 3 \mathrm{a}, 29 \%^{b}\left(\right.$ at $\left.25^{\circ} \mathrm{C}\right)$ & & \\
\hline
\end{tabular}

Moreover, this result shows a complementary reactivity of zinc salts with respect to copper ones in the reaction of enynones 1 with alkynes. Thus, while the use of $\mathrm{CuI}$ leads to the formation of a furyl allene, a known reactivity for copper carbenoids, $\mathrm{ZnCl}_{2}$ enables the cyclopropenation (Scheme 3). 12

Scheme 3. Complementary reactivity on enynones towards alkynes with copper and zinc salts.

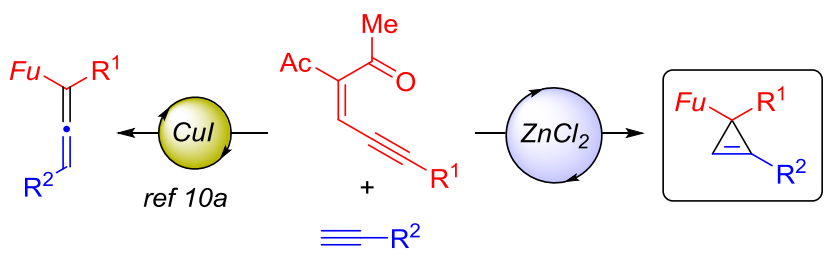

The scope of this transformation was subsequently explored (Scheme 4). Enynones 1 bearing alkyl groups at the alkyne terminus were first evaluated using differently substituted aromatic alkynes, affording cyclopropenes 3a-h in moderate yields. Interestingly, a cyclopropyl-substituted enynone afforded cyclopropenes $\mathbf{3 i}-\mathbf{j}$, which contain an uncommon [1,1'bi(cyclopropan)]-2-ene core. ${ }^{13}$ Moreover, aryl substituted enynones participated in the cyclopropenation reaction affording compounds 3k-n. ${ }^{14}$ When a 1,3-enyne was employed, cyclopropene 30 was chemoselectively obtained, as the alkene

moiety did not participate in the reaction. The use of alkylsubstituted alkynes proved more challenging. Thus, enynones bearing alkyl groups at substituent $\mathrm{R}^{3}$ did not give rise to the corresponding cyclopropene when using 1-pentyne, yet afforded a complex reaction mixture. In contrast, the reaction of phenyl-substituted enynone 1d with 1-pentyne led to cyclopropene $\mathbf{3 p}$, yet the yield was significantly lower and a stoichiometric amount of $\mathrm{ZnCl}_{2}$ was required. Further modifications on the structure of the enynones were also evaluated. Thus, cyclopropenes 3q-s were obtained in similar yields to those previously observed. As limitations, the present protocol proved not applicable to other terminal alkynes such as trimethylsilylacetylene or methyl propiolate, which gave rise to complex reaction mixtures. ${ }^{15}$

Scheme 4. Zinc-catalyzed cyclopropenation of terminal alkynes using enynones as carbene source: Scope. ${ }^{a}$

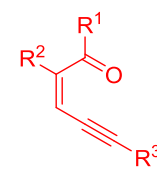

1

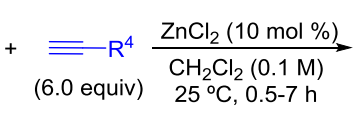

2
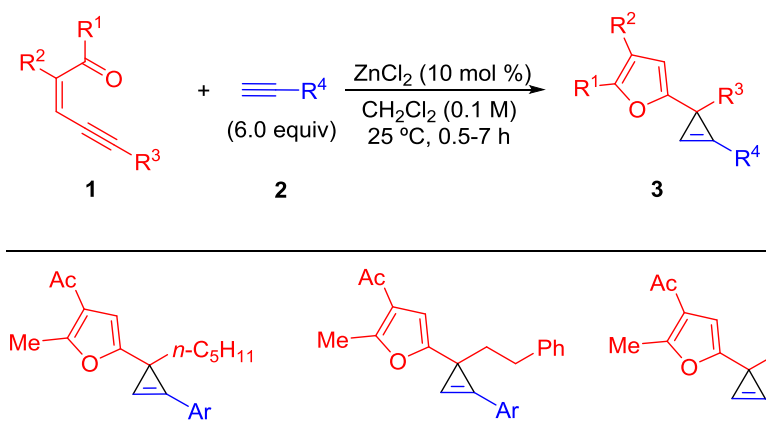

3a, $58 \%(\mathrm{Ar}=\mathrm{Ph})^{b}$

3b, $47 \%(\mathrm{Ar}=4$-Tolyl $)$

3c, $42 \%\left(\mathrm{Ar}=4-\mathrm{F}-\mathrm{C}_{6} \mathrm{H}_{4}\right)^{\mathrm{c}}$

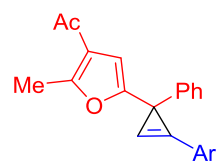

3k, 41\% $(\mathrm{Ar}=\mathrm{Ph})^{d}$ 3l, 52\% (Ar = 4-Tolyl $)^{d}$

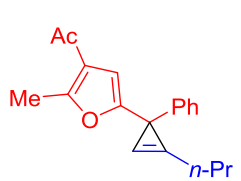

$3 p, 32 \%^{e}$

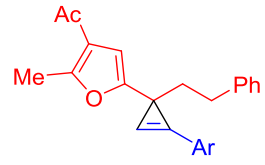

3d, $53 \%(\mathrm{Ar}=\mathrm{Ph})^{\mathrm{c}}$

$3 e, 44 \%(\mathrm{Ar}=4-\mathrm{Tolyl})$

3f, $55 \%\left(\mathrm{Ar}=3-\mathrm{MeO}-\mathrm{C}_{6} \mathrm{H}_{4}\right)$

$3 g, 53 \%\left(\mathrm{Ar}=4-\mathrm{F}-\mathrm{C}_{6} \mathrm{H}_{4}\right)$

3h, $30 \%\left(\mathrm{Ar}=4-\mathrm{F}_{3} \mathrm{C}-\mathrm{C}_{6} \mathrm{H}_{4}\right)$

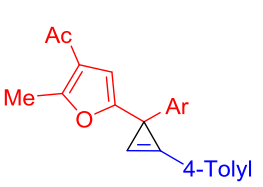

$3 \mathrm{~m}, 43 \%\left(\mathrm{Ar}=4-\mathrm{MeO}-\mathrm{C}_{6} \mathrm{H}_{4}\right)^{d}$

3n, $42 \%\left(\mathrm{Ar}=4-\mathrm{O}_{2} \mathrm{~N}-\mathrm{C}_{6} \mathrm{H}_{4}\right)$

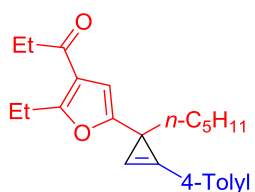

$3 q, 40 \%$

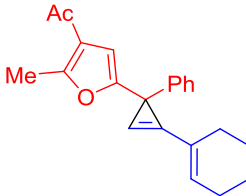

3o, $30 \%^{d}$

3i, 33\% $(\mathrm{Ar}=\mathrm{Ph})^{b}$

3j, 40\% (Ar $=4$-Tolyl $)$

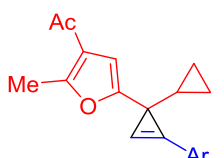
(n) 
group at $\mathrm{R}^{3}$ with various dialkyl-substituted alkynes under analogous reaction conditions $\left(10 \mathrm{~mol} \% \mathrm{ZnCl}_{2}, 6.0\right.$ equiv of the alkyne, $\mathrm{CH}_{2} \mathrm{Cl}_{2}$ at $25^{\circ} \mathrm{C}$ ) allowed the preparation of fully substituted cyclopropenes 3t-x in moderated yields (35-52\%). Unsymmetrically substituted alkynes could also be employed as exemplified with the preparation of compound $\mathbf{3 v}$. In contrast, the procedure is at this stage limited to alkynes bearing primary alkyl groups since we observed complex reaction mixtures or degradation of the starting materials when using internal alkynes bearing secondary/tertiary alkyl or aromatic substituents.

Scheme 5. Zinc-catalyzed cyclopropenation using internal alkynes. $^{a}$
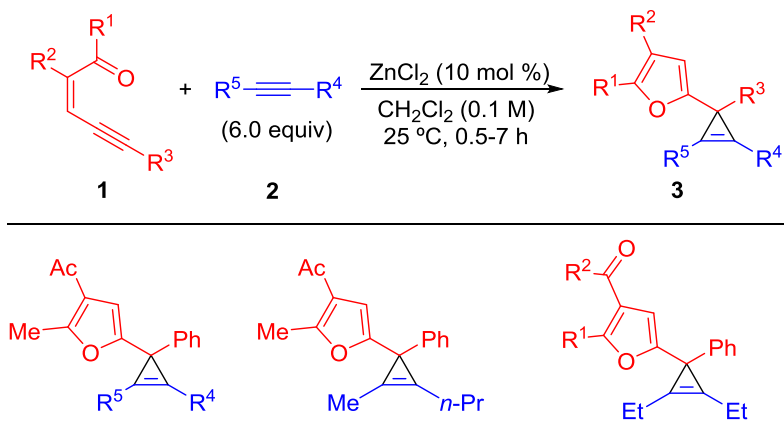

3t, $52 \%\left(R^{4}=R^{5}=E t\right)$

$3 v, 35 \%$

3w, $41 \%\left(R^{1}=R^{2}=E t\right)$

$3 u, 50 \%\left(R^{4}=R^{5}=B u\right)$ $3 \mathbf{x}, 43 \%\left(R^{1}=M e ; R^{2}=\right.$ OEt $)$

${ }^{a}$ Yields are referred to isolated product.

According to previous proposals, we believe that the formation of cyclopropenes $\mathbf{3}$ might occur through the formation of a zinc furyl carbene intermediate (see Scheme 1). ${ }^{8}$ The particular structure of this carbenoid, when compared with the one proposed for the Simmons-Smith reaction, seems to be the key for the subsequent steps. In analogy with the cyclopropanation reaction, ${ }^{8 \mathrm{a}}$ the formation of cyclopropenes $\mathbf{3}$ might occur via a concerted while asynchronous transition state in which bond formation to the terminal carbon proceeds earlier than the one involving the internal acetylenic carbon. ${ }^{17}$ However, different mechanisms could be operating, especially when using internal alkynes.

In summary, we have herein presented the first zinccatalyzed cyclopropenation reaction of alkynes, an unprecedented reactivity pattern in the chemistry of zinc carbenoids. This procedure makes use of easily available enynones $\mathbf{1}$ as the zinc carbenoid source and both terminal and internal alkynes. The results depicted in this work are in sharp contrast to previous studies involving zinc carbenoid-like species, which were incapable to promote cyclopropenation reactions. This preliminary study showed that the present transformation occurs with a remarkable ample scope, including challenging internal alkynes. Thus, a variety of relevant highly substituted cyclopropene derivatives $\mathbf{3}$ can be accessed in a simple manner. Interestingly, inexpensive and less-toxic $\mathrm{ZnCl}_{2}$ served as the catalyst, which operates under very mild reaction conditions. Further studies concerning mechanistic issues and the extension of the scope are currently ongoing.

\section{ASSOCIATED CONTENT}

\section{Supporting Information}

Experimental details and characterization data. This material is available free of charge via the Internet at http://pubs.acs.org.

\section{AUTHOR INFORMATION}

\section{Corresponding Author}

lalg@uniovi.es, vicenteruben@uniovi.es.

\section{Notes}

The authors declare no competing financial interest.

\section{ACKNOWLEDGMENT}

Financial support from MINECO of Spain (Grant CTQ201220517-C02-01) is gratefully acknowledged. R. V. is a Ramón y Cajal fellow. We thank Dr. E. Rubio (Universidad de Oviedo) and Dr. I. Merino (Universidad de Oviedo) for their assistance in the NMR study of compounds 4. We thank Prof. Dr J. M. González (Universidad de Oviedo) for his support.

\section{REFERENCES}

(1) Selected reviews on cyclopropanes: (a) Liu, H.-W.; Walsh, C. T. The Chemistry of the Cyclopropyl Group, Rappoport, Z. Ed., John Wiley \& Sons Ltd., New York, 1987; 959. (b) Wessjohann, L. A.; Brandt, W.; Thiemann, T. Chem. Rev. 2003, 103, 1625. (c) Rademacher, P. Chem. Rev. 2003, 103, 933.

(2) Selected reviews on cyclopropenes: (a) Rubin, M.; Rubina, M.; Gevorgyan, V. Chem. Rev. 2007, 107, 3117. (b) Zhu, Z.-B.; Wei, Y.; Shi, M. Chem. Soc. Rev. 2011, 40, 5534. (c) Rubin, M.; Rubina, M.; Gevorgyan, V. Synthesis 2006, 1221. (d) Baird, M. S. Chem. Rev. 2003, 103, 1271. (e) Phun, L. H.; Aponte-Guzman J.; France, S. Synlett 2012, 2723.

(3) Simmons, H. E.; Smith, R. D. J. Am. Chem. Soc. 1958, 80, 5323.

(4) (a) Furukawa, J.; Kawabata, N.; Nishimura, J. Tetrahedron Lett. 1966, 7, 3353. (b) Lebel, H.; Marcoux, J.-F.; Molinaro, C.; Charette, A. B. Chem. Rev. 2003, 103, 977.

(5) (a) Denmark, S. E.; Edwards, J. P.; Wilson, S. R. J. Am. Chem. Soc. 1991, 113, 723. (b) Denmark, S. E.; Edwards J. P.; Wilson, S. R. J. Am. Chem. Soc. 1992, 114, 2592. (c) Charette, A. B.; Marcoux, J.F. J. Am. Chem. Soc. 1996, 118, 4539. (d) Charette, A. B.; Marcoux, J.-F.; Bélanger-Gariépy, F. J. Am. Chem. Soc. 1996, 118, 6792. (e) Charette, A. B.; Marcoux, J.-F.; Molinaro, C.; Beauchemin, A.; Brochu, C.; Isabel, E. J. Am. Chem. Soc. 2000, 122, 4508.

(6) (a) Vo-Quang, L.; Cadiot, P.; Willemart, A. Compt. Rend. 1962, 255, 950. (b) Castellucci, N. T.; Griffin, C. E. J. Am. Chem. Soc. 1960, 82, 4107. (c) Jautelat, M.; Schwarz, V. Tetrahedron Lett. 1966, 7, 5101. (d) Wittig, G.; Hutchison, J. J. Liebings Ann. Chem. 1970, 741,79 . For reactions of alkynylimines with zinc carbenoids leading to bicyclo[1.1.0]butanes and rearrangement products, see: (e) Wipf, P.; Stephenson, C. R. J.; Okumura, K. J. Am. Chem. Soc. 2003, 125, 14694.

(7) For selected recent examples of metal-catalyzed cyclopropenations using diazocompounds as the carbene source, see: (a) Briones, J. F.; Davies, H. M. L. J. Am. Chem. Soc. 2012, 134, 11916. (b) Briones, J. F.; Hansen, J.; Hardcastle, K. I.; Autschbach, J.; Davies, H. M. L. J. Am. Chem. Soc. 2010, 132, 17211. (c) Lindsay, V. N. G.; Fiset, D.; Gritsch, P. J.; Azzi, S.; Charette, A. B. J. Am. Chem. Soc. 2013, 135, 1463. (d) Cui, X.; Xu, X.; Lu, H.; Zhu, S.; Wojtas, L.; Zhang, X. P. J. Am. Chem. Soc. 2011, 133, 3304.

(8) (a) Vicente, R.; González, J.; González, J.; Riesgo, L.; López, L. A. Angew. Chem. Int. Ed. 2012, 51, 8063. (b) González, J.; López, L. A.; Vicente, R. Chem. Commun. 2014, 8536. See also: (c) Song, B.; Li, L.-H.; Song, X.-R.; Qiu, Y.-F.; Zhong, M.-J.; Zhou, P.-X.; Liang, Y.-M. Chem. Eur. J. 2014, 20, 5910.

(9) For recent reviews on zinc catalysis in organic chemistry, see: (a) Enthaler, S. ACS Catal. 2013, 3, 150. (b) Wu, X.-F. Chem. Asian J. 2012, 7, 2502. (c) Wu, X.-F.; Neumann, H. Adv. Synth. Catal. 2012 , 254,3141 . For selected examples of zinc-catalyzed transformations, 
see: (d) Sniady, A.; Durham, A.; Morreale, M. S.; Wheeler, K. A.; Dembinsky, R. Org. Lett. 2007, 9, 1175. (e) Alex, K.; Tillack, A.; Schwarz, N.; Beller, M. Angew. Chem. Int. Ed. 2008, 47, 2304. (f) Studte, C.; Breit, B. Angew. Chem. Int. Ed. 2008, 47, 5451. (g) Sugiishi, T.; Nakamura, H. J. Am. Chem. Soc. 2012, 134, 2504. (h) Nagashima, Y.; Takita, R.; Yoshida, K.; Hirano, K.; Uchiyama, M. J. Am. Chem. Soc. 2013, 135, 18730.

(10) (a) Hu, F.; Xia, Y.; Ma, C.; Zhang, Y.; Wang, J. Org. Lett. 2014, 16, 4082. For other examples of the reactivity of copper carbenes with alkynes to yield allenes, see: (b) Xiao, Q.; Xia, Y.; Li, H.; Zhang, Y.; Wang, J. Angew. Chem. Int. Ed. 2011, 50, 1114. (c) Hossain, M. L.; Ye, F.; Zhang, Y.; Wang, J. J. Org. Chem. 2013, 78, 1236. When the reaction was accomplished with $\mathrm{ZnCl}_{2}$ in the presence of bases $\left(\mathrm{K}_{2} \mathrm{CO}_{3}\right.$ or $\left.i-\mathrm{Pr}_{2} \mathrm{NEt}\right)$, allene derivatives were not detected, yet significantly lower yields of cyclopropene $\mathbf{3 a}$ were observed.

(11) The use of rhodium catalysts under otherwise identical reaction conditions leads to a cascade sequence involving the participation of cyclopropenes, which could be isolated only in few cases, see: González, M. J.; López, E.; Vicente, R. Chem. Commun. 2014, 5379.

(12) For reviews on furans, see: (a) Wong, H. N. C.; Hou, X.-L.; Yeung, K.-S.; Huang, H. in Modern Heterocyclic Chemistry (Eds.: Álvarez-Builla, J.; Vaquero, J.-J; Barluenga, J.), Wiley-VCH, Meinheim, 2011. (b) Boto, A.; Álvarez, L. in Heterocycles in Natural Products Syntheis (Eds.: Majumdar, K. C.; Chattopdahyay, S. K.), Wiley-VCH, Meinheim, 2011. (c) Keay, B. A.; Dibble, P. W. in Comprehensive Heterocyclic Chemistry II, (Eds.: Katritzky, A. R.; Rees, C. W.; Scriven, E. F. V.), Elsevier, Oxford, 1997, Vol. 2, 395. For selected examples of relevant compounds containing furans, see: (d) Cui, X.; Xu, X.; Wojtas, L.; Kim, M. M.; Zhang, X. P. J. Am. Chem. Soc. 2012, 134, 19981. (e) Woo, C. H.; Beaujuge, P. M.; Holcombe, T. W.; Lee, O. P.; Fréchet, J. M. J. J. Am. Chem. Soc. 2010, 132, 15547. (f) Gidron, O.; Diskin-Posner, Y.; Bendikov, M. $J$. Am. Chem. Soc. 2010, 132, 2148.

(13) An enynone bearing a tert-butyl group at the alkyne terminus did not react with the alkyne under similar reaction conditions.

(14) Compounds 4 (major diastereoisomer shown below) were in some cases obtained. The formation of $\mathbf{4}$ involves the coupling of two molecules of the corresponding enynone (in black) and one of the alkyne (in red). Attempts to increase the yield of compounds $\mathbf{4}$ using an excess of the corresponding enynone were unsuccessful. It should be noted that compounds $\mathbf{4}$ do not arise from the corresponding cyclopropenes 3. See the Supporting Information for further details.

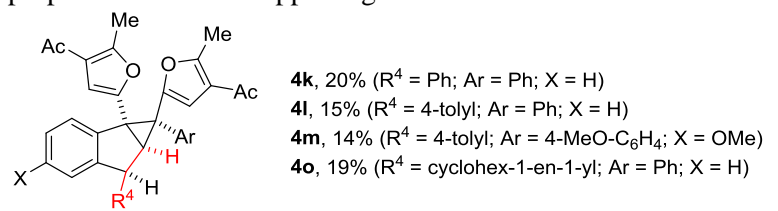

(15) Attempts to accomplish a zinc-catalyzed one-pot cascade sequence through the generation of the enynone 1 via Knoevenagel condensation proved unsuccessful since complex reaction mixtures were obtained under a variety of reaction conditions.

(16) For a silver-catalyzed cyclopropenation of internal alkynes with diazocompounds as the carbene source, see: Briones, J. F.; Davies, H. M. L. Org. Lett. 2011, 13, 3984.

(17) A similar mechanism has been proposed in the cyclopropenation of terminal alkynes with rhodium carbenoids, see: Nowlan III, D. T.; Singleton, D. A. J. Am. Chem. Soc. 2005, 127, 6190. 